\title{
Do processo criminal para as páginas jornalísticas: aspectos da religiosidade popular em Palmas/PR (1907)
}

\author{
Precila Kátia Moreira*
}

\author{
Palavras-chave: \\ Religiosidade Popular \\ Cultura Cabocla \\ Campos de Palmas
}

Keywords:

Popular Religiousness

Cabocla Culture

Palmas de Campos

\begin{abstract}
Resumo: A religiosidade popular é incluída como grande temática neste artigo, mas a atenção se volta para imprensa escrita diante de casos religiosos presenciados pela população. A problemática atenta-se para o contexto histórico da região dos Campos de Palmas no sudoeste do Paraná e acerca o objetivo geral da pesquisa que visa analisar aspectos da religiosidade popular, experimentados por parcelas da população local, em um momento em que a Igreja Católica investia na romanização da religião. $\mathrm{O}$ caso analisado é um processo-crime de 1907, resultante de uma prática de exorcismo na localidade de Alegria no município de Palmas/PR. A base documental utilizada como fonte histórica para esse artigo são recortes jornalísticos da imprensa escrita, além do processo criminal, assim promovendo um diálogo por meio do cruzamento das fontes. Com isso, possibilita-se uma percepção maior do contexto, aproximando o cotidiano dos sujeitos envolvidos no caso para compreender as experiências religiosas vivenciadas.
\end{abstract}

\begin{abstract}
Popular religiosity is included as a great theme in this article, but the attention is turned to the written press in front of religious cases witnessed by the population. The problem is focused on the historical context of the Campos de Palmas region in southwestern Paraná and the general objective of the research is to analyze aspects of popular religiosity experienced by the local population at a time when the Catholic Church invested in The romanization of religion. The case analyzed is a criminal case of 1907, resulting from an exorcism practice in the town of Alegria in the municipality of Palmas/PR. The documentary base used as a historical source for this article are newspaper clippings of the written press, in addition to the criminal process, thus promoting a dialogue through the crossing of sources. With this, allowing a greater perception of the context, bringing the daily life of the subjects involved in the case to understand the religious experiences experienced.
\end{abstract}

Recebido em 31 de maio de 2017. Aprovado em 07 de agosto de 2017.

\section{Introdução}

Em certos períodos históricos, muitas manifestações e práticas religiosas populares foram taxadas pela imprensa escrita como fanatismo. Com o título "Crime e fanatismo em Palmas", em 20 de março de 1907, o jornal curitibano $A$ República ${ }^{1}$, denunciou um crime de homicídio ocorrido na comunidade de Alegria, interior da comarca município de Palmas, no Paraná. O jornal prosseguiu com a frase: "Subordinada às vistosas epigraphes de Monge Custodio, mulher é carbonizada" (A REPUBLICA, 1907, p. 2), ressaltando que o ocorrido, o assassinato de uma mulher chamada Eogenia Maria Balbina, deuse em função de que esta foi submetida a práticas religiosas, de expulsão de demônios, por parte de um indivíduo vulgarmente conhecido como "Anjo Custodio", auxiliado por outrem.

Ocorrido no alvorecer do regime republicano, envolto em discursos de progresso e políticas de desenvolvimento, o crime, qualificado como "bárbaro", foi resultante de uma prática de exorcismo ${ }^{2}$ e chegou a ser destaque em outros jornais do estado ${ }^{3}$. O caso foi investigado pelo Fórum da Comarca de Palmas e originou um processo-crime, utilizado nesse trabalho como uma das principais fontes de análise, juntamente

\footnotetext{
* Graduada em Licenciatura em História pela Universidade Federal da Fronteira Sul (UFFS). Atualmente, é docente na disciplina de História na Rede Municipal de Educação de Chapecó - SC.

E-mail: precilakatia@hotmail.com.
} 
com fontes jornalísticas, que fazem referência à repercussão do crime.

Assim, a pesquisa se utiliza do processo criminal em que investiga condicionantes para compreender pontos de uma sociedade, seja no sentido político, social e, com maior ênfase, culturalmente. $\mathrm{O}$ caso foi julgado entre os anos de 1907 a 1909. E, de forma minuciosa, analisaramse as fontes, o que, na perspectiva da microanálise, inaugurada por historiadores como Giovani Levi e Carlo Ginzburg, permite que se compreendam aspectos sociais diversos, "captados nas entrelinhas".

Não é apenas entender um indivíduo, mas os significados da sociedade - quando se estuda o indivíduo principal da pesquisa (Anjo Custódio), faz-se necessário compreender outros elementos da época (sociais, culturais, políticos, religiosos), ou seja, também é importante estudar um vasto segmento da sociedade na virada do século XIX para o XX.

Sobre as duas fontes históricas da pesquisa, vale ressaltar que foi investigado, no Superior Tribunal de Justiça do Estado do Paraná (STJPR), o Processo de Apelação Crime de no 527, do ano de 1907, cujos réus foram "Custodio Ferreira Soares e outros". Esse processo-crime, além da estrutura, mostra a pluralidade dos discursos presente no processo ${ }^{4}$. E como fonte principal de discussão, utilizam-se as fontes jornalísticas que fazem referência à repercussão do crime, os quais nos fornecem informações na reconstituição do caso. Essas fontes são jornais retirados do acervo digital do site da Hemeroteca Nacional Digital ${ }^{5}$, nos quais, ao reportá-los, também se manteve a grafia da época ${ }^{6}$. O primeiro é o jornal A Republica com o seguinte recorte do texto "Crime e Fanatismo em Palmas”, publicado em 20 de março de 1907. O segundo é o jornal A Noticia com o recorte do texto "Monge Custodio - Mulher carbonizada: mulheres e creanças queimadas" também publicado em 20 de março de 1907. Destaca-se que, os dois jornais fazem referência ao jornal $O$ Palmense (porém, a reportagem desse não será analisada). Além desses dois jornais, O Commercio faz menção sobre andar do processo em publicações de 17 de março de 1909.
Por meio da análise, pode-se perceber como a imprensa e o poder judiciário constroem "verdades", ao classificarem os indivíduos enquadrando-os em determinados rótulos, tais como: loucos, bárbaros, delinquentes, criminosos e fanáticos. Portanto, as fontes podem nos ajudar a desvendar o comportamento de uma massa desclassificada ou de um segmento excluído, e nos possibilitam observar os fluxos que conduzem os sujeitos, a sociedade e os interesses dos envolvidos, analisando as regras de convívio da época.

\section{Palmas na virada do século XIX para o XX}

Os Campos de Palmas/PR foram considerados uma região fértil, rica e disputada, ocasionando conflitos jurídicos, políticos e sociais. Essas disputas não ficaram somente em âmbito regional, nos limites do Brasil. A Argentina também reivindicou parte das terras, ocasionando a Questão de Palmas ou Misiones.

Em 1853, por questões políticas, a região se desmembrou da vinculação com São Paulo. Somente em 1895, a Questão de Palmas foi decidida por arbitramento confiado ao Presidente americano Grover Cleveland, que deu ganho de causa para o Brasil, sob protesto da Argentina. Ainda como Campos de Palmas, a região foi denominada e elevada a diferentes categorias (de vila a município) por diversas legislações ${ }^{7}$. Uma dessas, em 13 de abril de 1877, pela Lei Provincial no 848, a Freguesia de Palmas foi elevada à categoria de Vila ${ }^{8}$; consequentemente, tornou-se um Município autônomo (LAGO, 1987, p. 77).

Além disso, diante do cenário nacional, quando se intensificava o povoamento dessa região - mais tarde configurada como sudoeste do Paraná e oeste de Santa Catarina -, o presente trabalho visou a analisar aspectos da religiosidade popular, experimentados por parcelas da população local, em um momento em que a Igreja Católica investia na romanização da religião, ou seja, na imposição do Catolicismo oficial, tridentino.

Isso porque, até fins do século XIX as regiões Oeste e Sudoeste do Paraná eram consideradas periféricas, não integradas às regiões mais dinâmicas do país, segundo o olhar do Estado. Por 
isso, houve iniciativas que vislumbraram a região de outras formas, buscar o povoamento da região com a entrada de imigrantes motivados pelos discursos do Regime Republicano. Trata-se, também, de um momento em que a Igreja Católica envidou esforços na tentativa de estabelecer uma religião acordando com suas doutrinas.

Sobre o incentivo religioso na região, é valido salientar que no início do século $\mathrm{XX}$, a paroquia de Palmas passou a ser atendida pelos padres franciscanos, os quais, segundo Paulo Diel, "[...] quase todos oriundos da Alemanha, vinham imbuídos do ideal de reforma" (DIEL, 2001, p. 100) e apoiavam a implantação de um catolicismo oficial, que fizesse frente às práticas de religiosidade popular predominantes.

Observa-se, também, que a política e a religião andavam de mãos dadas, pois naquele momento, a elaboração e o controle dos registros cíveis ficavam sob a responsabilidade da Igreja; assim, conforme explica Lago (1987, p. 77), era “[...] difícil separar o aspecto religioso do político, principalmente porque, até a Proclamação da República do Brasil, a Igreja era a responsável pelos registros civis. Além disso, praticamente todos os atos políticos processavam-se ligados à Igreja".

No sentido social, juntamente com a população que migrou de outras partes do país, bem como os imigrantes ou descendentes destes, também não se pode deixar de citar nesse encontro de sujeitos, os escravos (em fins do século XIX, eles se tornaram libertos, passando a se identificarem como ex-escravos) trazidos para a lida nas fazendas, os indígenas nativos e os caboclos?. Sua cultura, expressa por meio de religiosidade, oralidade, crenças, hábitos e rituais também contribuiu para a formação das características socioculturais da região.

Por conseguinte, as condições em que se deu o homicídio evidenciam um conjunto de contradições existentes entre os debates de cunho positivista que embasaram a criação da jovem República e a realidade vivenciada por parcelas da população, as quais, nesse caso, encontravam-se afastadas dos grandes centros urbanos.

\section{O crime ocorrido nos campos de palmas em 1907}

No segundo dia do mês de março de 1907, na localidade denominada Alegria em terreno da Fazenda da Cruz, demarcada na época a cinco léguas de Palmas/PR, os denunciados Custodio Ferreira Soares e Manoel Antonio Ferreira produziram na mulher Ignácia Trindade e nas meninas Maria Angela, Bibiana e Lourença queimaduras pelo corpo. O principal ato criminal dos indiciados foi o espancamento "bárbaro" com varas de marmelo e rabo de tatú na mulher Eogenia Maria Balbina, os quais, lançando mão de um lenço, a asfixiaramna até a morte. Posteriormente, os homens teriam realizado seu velório às escusas, e somente a comunidade local se fez presente.

O jornal curitibano A Republica (1907, p. 2) descreve as circunstâncias do ocorrido. Destaca que os indivíduos autores do crime eram "[...] dois desses míseros exploradores da crendice humana, cuja deambulação pelos nossos sertões onde vulgarmente conhecidos pela designação de monges" (p. 2), e ainda que "[...] o Messias é um alentado e esperto caboclo intitulado Anjo Custodio e que se fazia acompanhar de outro individuo, seu acolyto, Manoel Antonio" (p. 2), espalhando sua crença. $O$ jornal define essa crença como sendo "[...] extrema ao fanatismo sem o menor resquício de moral, fascinando a gente ingênua com as promessas de eterna salvação, mediante alguns proventos" (p. 2).

A vítima principal era de "[...] uma pobre família de caboclos, gente simples e de espirito sempre prompto a se deixar empolgar pela convicção nas crenças absurdas desses profetas sertanejos" (p. 2); e, para convencer a mulher Eogenia Maria Balbina e seu marido, Custodio teria mostrado "[...] uma trança de cabellos e grão de milho que havia tirado do corpo de outra mulher (!), que escapara milagrosamente das caldeiras de Pero Botelho" (A NOTICIA, 1907, p. 1) por "intercessão d'elle" (p. 1). Posteriormente a isso, Custodio teria convencido Eogenia de estar com "[...] o diabo no corpo e que só ele seria capaz de tirar-lhe, reenviando-o imediatamente para o reino das trevas, precisava, porém, que a endemoninhada se 
submetesse à uma dura expiação" (p. 1). Por conta disso, a "inditosa sertaneja, convicta de sua desgraça [...] sujeitou-se resignadamente á prova que lhe seria applicada pelo monge Custodio. Este fanático tendo reduzido Eugenia a esse grau de [...] obediência" (A REPUBLICA, 1907, p. 2), deu, então, início à sessão do referido tratamento.

Assim, as práticas religiosas aplicadas foram inicializadas com uma medicação para "[...] a delicada operação de extrahir morto o demônio, a fórtes doses de $\operatorname{tartaro}^{10}$ ministrada à infeliz. Mas o demo não sahio, e Eugenia sentindo-se extenuada pelos effeitos do terrível drástico cahio inane n'uma cama" (A REPUBLICA, 1907, p. 2). Sobre esse ponto do medicamento, trata-se de uma substância utilizada para determinadas mazelas.

Em seguida, cita o jornal cita que o "[...] monstruosos caboclo, sentindo despertar os seus instinctos de féra, pegou em dois filhos d'aquella e os arremessou ao fogo que ardia na cosinha da casa, queimando barbaramente os innocentes". Essa cena "[...] foi desenrolada á vista do pae dos menores, o qual condoido da sorte de seus filhos, mais acobardado, pedia de joelhos ao inquisidor que não os matasse" (A REPUBLICA, 1907, p. 2). Aqui, percebe-se a pressão do jornal ao descrever situação de desconforto do pai fazendo que ficasse ainda maior.

Nessa ocasião, a casa de Eogenia já estava movimentada com mais pessoas, chegando também a esposa do dito Manoel Antonio Ferreira, de nome Ignácia Maria da Trindade, em que “[...] o monge ao avistar vaticinou-lhe também ter o diabo no corpo e que para salval-a era preciso assentar se no fogo, o que Ignacia immediatamente fez causando-lhe queimaduras nas nadegas e nas mãos, conquanto negue" (A REPUBLICA, 1907, p. 2). Mas Ignacia “[...] não queria mais passar pelas chammas purificadoras, pegou duas creanças, Maria Angela e Bibiana, tendo esta quatro mezes de idade e com as duas primeiras ficarão também queimadas" (1907, p. 2). Nesse trecho, jornal demonstrou indignação. Puderam ser identificadas mais vítimas que foram submetidas a tais práticas religiosas, e adiante faremos esse adendo.
E a referida sessão não terminou. Segundo o jornal A Republica, o referido "[...] monge principiou a rezar. Eugenia delirando levantou-se e veio até a cosinha, ahi então o seu primo Manoel, armado de um rabo de tatú desancou na infeliz uma valente sova a pedido do Anjo Custodio" (1907, p. 2). Depois de surrá-la com rabo de tatú, “[...] o monge mandou buscar algumas varas de marmello e durante seis horas elle e Manoel surraram a valer a pobre peccadora" (p. 2). Além da surra, Eogenia foi segurada "pelas duas féras e passada pelo fogo". E, por fim, o último método aplicado foi com “[...] um lenço que Manoel trazia foi passado ao pescoço de Eugenia até que exalou o ultimo sopro de vida" (p. 2), sendo esse procedimento corrobora com os Autos do Corpo de Delito de Eogenia, que sua morte foi ocasionada por estrangulação - destacando também as escoriações pelo corpo.

\section{Os aspectos da religiosidade e tratamento da imprensa}

O fato chegou a conhecimento da polícia no dia 4 do mês corrente, ou seja, somente dois dias depois, quando o corpo de Eogenia encontrava-se sepultado - no entendido dos editores dos jornais, o corpo encontrava-se insepulto, talvez indicando que não teria sido oficializado seu enterro (perante a Igreja). Seguindo, o Alferes comissário de polícia, acompanhado do escrivão e três praças, dirigiu-se ao local para retirada do cadáver e averiguações. O corpo foi encaminhado para exame cadavérico pelos Drs. Moreira Sampaio e Jocelin Bahll, e às quatro horas da tarde foi realizado o sepultamento de Eogenia Maria Balbina. E, conforme relatam os jornais e pela circulação das informações do acontecimento recolhidos nos depoimentos, teria sido muito concorrido o seu enterro.

Notícias do ocorrido circularam pela região de Palmas e na capital do Paraná. Para a época, os textos publicados nos dois jornais eram longos, com incisivas opiniões sobre o fato e contendo expressões fortes, reportando-se ao Monge Custodio como tomado de um "instincto de féra" (A REPUBLICA, 1907, p. 2); ou, ainda, rotulando os interventores de "míseros exploradores da crendice humana", "este fanático" (A NOTICIA, 1907, p. 1). 
Nesse sentido, os jornais, tendo em vista a imprensa escrita, promovem um debate acerca das expressões transcritas no bojo de seus textos. Sobre a intencionalidade de cada jornal como fonte, não se faz uma análise sobre a formação teórica e/ou filosófica dos escritores, nem mesmo com maior ênfase - por mais necessário que fosse - sobre as visões política ou apolítica dos responsáveis pelos jornais em Curitiba/PR, muito menos a que público está sendo direcionada a circulação de cada periódico. O que pode ser indicado como hipótese, é que vários jornais dessa época tinham como seus donos, membros da comunidade jurídica, alguns deles juízes e promotores ${ }^{11}$.

Como vimos, com grande abrangência o jornal A República publicou um longo texto diante do caso, sem indicar autoria e sob o título "Crime e Fanatismo em Palmas", aplicando de forma incisiva a reportagem, deixando explícito sua indignação diante do crime e utilizando frases como "tragicas e repugnantes scenas" (A REPUBLICA, 1907, p. 2). Além de criticar de forma abrupta a crença e suas práticas populares citando-as como "fanatismo".

O outro jornal de circulação em Curitiba, A Notícia, também escreveu um longo texto, com autoria do jornalista Antonio R. de Macedo, tendo como título "Monge Custodio - mulher carbonizada: mulheres e creanças queimadas", e referencia o jornal $O$ Palmense. Percebe-se sua crítica quando citam o Custodio como "[...] o enviado de Deus, para a remissão dos peccados e a eterna salvação das almas transviadas" (A NOTICIA, 1907, p. 1), podendo assim, problematizarmos a visão dos letrados diante do ocorrido.

Esse crime chama-nos atenção em diversos aspectos, principalmente se considerarmos alguns parâmetros recorrentes em crimes, sejam: pelo grau de violência considerando o crime em si, pelo perfil da vítima ou do autor(es), pelos motivos que se levou ao ato, pelos desdobramentos que o fato alcançou ou pelas circunstâncias que levaram ao crime. Por isso, esse crime chamou atenção e converteuse em objeto de pesquisa pela singularidade das circunstâncias em que ocorreu.
O crime combina violência psicológica - a vítima Eogenia foi forçada a confessar que tinha um mau espírito em seu corpo, além de ser induzida a queimar sua própria filha; posteriormente, foi obrigada a ingerir duas dosagens de tártaro - e física, como surras com varas de marmelo e rabo de tatu, sofridas por Eogenia e Ignácia, e estrangulamento com lenço (Eogenia). As vítimas (três crianças e duas mulheres) foram forçadas a passar pelo fogo e sofreram queimaduras pelo corpo.

Sobre o ato, adentramos no principal elemento que gira em torno do que na religiosidade popular chama-se de rituais. O primeiro ritual é o batismo, no qual se pode perceber que foi visto como símbolo de passagem e como uma tentativa de salvação. Já o segundo ritual é o exorcismo, nesse listamos momentos em que a vítima principal, Eogenia Maria Balbina, foi submetida, como: a possessão e o delírio (investidas psicológicas); a surra com varas e rabo de tatú; a passagem pelo fogo; a estrangulação (todas essas investidas físicas). E, embora detalhadas de forma particular, fizeram parte do conjunto do procedimento de exorcismo.

Nesse sentido, trazem-se como elementos a instrumentalização de feitiçaria e benzedura utilizada: o medicamento; os objetos extraídos da natureza como as ervas, as varas de marmelo e o rabo de tatú; e por fim, outros materiais ligados à devoção: o rosário e a vela. Todos esses interligados com as práticas religiosas da experiência vivenciada por parte da população cabocla.

Utilizando dados e informações oferecidos pelos indivíduos que prestaram testemunho, mesmo que de forma rápida, foi possível conhecer um pouco mais sobre seus perfis. É possível identificar características de grupos sociais, observar a região de onde são oriundos, conhecer o modo de vida ou profissão, verificar idade, escolaridade, entre outros detalhes.

Para uma melhor visualização, segue o Quadro 1 com detalhes sobre os envolvidos no crime. 
Quadro 1 - Dados dos envolvidos no momento do crime e demais testemunhas:

\begin{tabular}{|c|c|c|c|c|c|c|}
\hline Nome & $\begin{array}{c}\text { Função } \\
\text { atribuída no } \\
\text { processo }\end{array}$ & Idade & $\begin{array}{c}\text { Estado } \\
\text { Civil }\end{array}$ & Naturalidade & Profissão & $\begin{array}{l}\text { Sabe ler/ } \\
\text { escrever }\end{array}$ \\
\hline Custodio Ferreira Soares & Réu & 30 & Solteiro & Paraná & Lavrador & Não \\
\hline Manoel Antonio Ferreira & Réu & 24 & Casado & Palmas/PR & Lavrador & Não \\
\hline Eogenia Maria Balbina & Vítima & - & - & - & - & - \\
\hline Maria Angela & Vítima & 4 & Solteira & - & - & - \\
\hline Bibiana & Vítima & -1 & Solteira & - & - & - \\
\hline Lourença & Vítima & - & Solteira & - & - & - \\
\hline Ignácia Maria da Trindade & Vítima/Test & 22 & Casada & Palmas/PR & - & Não \\
\hline Joanna Balbina Ferreira dos Santos & Testemunha & 45 & Casada & Palmas/PR & - & Não \\
\hline João Soares Branco & Testemunha & 30 & Viúvo & Paraná & Lavrador & Não \\
\hline Francisco José de Lima & Testemunha & 40 & Solteiro & Paraná & Lavrador & Não \\
\hline João Francisco Belarmino & Testemunha & 28 & Solteiro & $\mathrm{SC}$ & Lavrador & Não \\
\hline João Bernardo de Oliveira & Testemunha & 40 & Casado & SC & Lavrador & Não \\
\hline Maria da Gloria Ferreira & Testemunha & 20 & Casada & Palmas/PR & - & Não \\
\hline Pedro Ferraz dos Santos & Testemunha & 58 & Solteiro & Palmas/PR & Lavrador & Não \\
\hline Ignácia Fagundes da Silva & Testemunha & 49 & Casada & Paraná & $\begin{array}{c}\text { Empregada } \\
\text { Municipal }\end{array}$ & Sim \\
\hline Tristão José de Araújo & Testemunha & 56 & Casado & Paraná & $\begin{array}{c}\text { Empregado } \\
\text { Municipal }\end{array}$ & Sim \\
\hline
\end{tabular}

Fonte: (STJ-PR, 1907).

Sobre o perfil das vítimas: Eogenia Maria Balbina (vítima de morte), mulher, preta (como foi designada pelo promotor e parte das testemunhas), não sabia ler nem escrever, e não foi indicado um ofício de trabalho - é muito provável fosse cuidadora do lar ou, mais popularmente, dona de casa -; sobre Ignácia Maria da Trindade, mulher do segundo indiciado, Manoel Antonio Ferreira, não foi detalhado o seu perfil, nem na identificação inicial, nem no auto de corpo de delito, nem mesmo relatado por testemunhas ou promotores; porém, sabe-se que não sabia ler nem escrever e também não foi indicada nenhuma profissão (ofício) de trabalho. Assim, reforça-se o conceito histórico de "caboclo" como um personagem mestiço de origem pobre.

Também se consideram as três crianças ${ }^{12}$ que constam autos de corpo de delito: duas delas, Maria Angela e Bibiana (com quatro meses de vida), estas filhas de Ignácia, e a outra é Lourença, filha de Eogenia. Também se sabe que Eogenia tinha outra filha, que se chamava Palmira, e esta foi citada rapidamente no processo como vítima, o que também foi relatado nos jornais, embora não tenha sido realizado corpo de delito.

Sobre o perfil dos autores do crime, temos como principal autor Custodio Ferreira Soares, intitulado por testemunhas como monge e curandeiro. Não tinha uma residência fixa, e vivia na localidade, há aproximadamente um ano, na casa de Fortunato Caetano. Sobre sua profissão ou meio de vida, foi identificado como lavrador. O segundo indiciado, Manoel Antonio Ferreira, era esposo da vítima Ignácia Maria da Trindade e pai das crianças Maria Angela e Bibiana. Segundo testemunhas, era um homem tranquilo e não havia demonstrado indícios de violência até então. Residia na localidade desde que nasceu e também declarou ser lavrador, considerando esta como sua profissão ou meio de vida.

Deve-se, ainda, considerar o perfil das testemunhas. Ao logo do processo, foram inquiridas 12 pessoas para declararem suas posições sobre o caso; contudo, temos o relato de dez testemunhas, e três dessas depuseram duas vezes. Os faltantes foram: Clemencia Maria Bitta (mãe do indiciado 
Manoel) e Fortunato Caetano (que oferecia estadia ao indiciado Custodio). É importante salientar que o padrinho da vítima Eogenia e compadre do indiciado Manoel, Benedicto Manoel Antonio, Brandina (amasiada com João Belarmino) e Domingos Ferreira, segundo testemunhas, presenciaram o acontecimento, mas não foram chamados para depor.

Considerando o perfil das testemunhas, cinco dessas intitularam-se como lavradores (os homens), duas testemunhas são empregadas municipais e três não citaram nenhum ofício de trabalho (as mulheres) - provavelmente estas eram 'cuidadoras do lar', algo que para a época não se considerava como profissão ou meio de vida. Além dessas considerações, somente duas das testemunhas sabiam ler e escrever (empregados municipais).

Outro parâmetro com relação às circunstâncias de tais práticas religiosas, destaque da pesquisa, é pelo fato de que o réu principal, Custodio Ferreira Soares - seja por razões pessoais ou religiosas - esteve fazendo um procedimento espiritual (prática religiosa) julgando ser necessário para libertar a vítima de um mau espírito que dizia estar habitando no corpo dela. Sendo assim, o ato criminal foi justificado pelo seu principal autor (e por algumas testemunhas) como resultado de uma prática que combinava elementos de religiosidade e medicina populares.

Além disso, é fundamental considerar que na cidade de Palmas a repercussão do caso também sofreu impactos, pois até mesmo as pessoas que não tiveram envolvimento direto no crime tinham suas especulações sobre o ocorrido. No seguinte trecho do Processo-crime 527, observam-se as declarações de duas testemunhas, residentes de Palmas e que trabalham como empregados municipais. Ignácia Fagundes da Silva depõe

[...] que tem conhecimento do facto, não porque o tivesse assistido mas porque ninguem nesta Cidade ignora que os denunciados se achãm prezos por terem em principios do mez de Março morte a uma mulher de cor preta, depois de lhe ter dado uma grande sóva para tirar o diabo que diziãm ter ella no corpo, e de terem queimado duas criansas que ainda aprezentavãm as cicatrizes das queimaduras, filhas do denunciado Manoel pelo mesmo motivo. (STJ-PR, 1907, f. 51).

$\mathrm{Ou}$ seja, a testemunha comenta que a cidade estava ciente do fato ocorrido até porque os denunciados se encontravam presos e pelas circunstâncias do crime. O motivo da detenção dos indiciados, entendida pela testemunha, seria pelo assassinato de uma mulher de cor "preta" depois de terem espancado a vítima com a justificativa de libertá-la do mau que havia "possuído-a" e, também, porque pelo fato de terem queimado duas crianças - filhos(as) do réu Manoel - pelo dito motivo religioso. Não citando também a filha de Eogenia, a qual também havia sido queimada na ocasião.

O último ponto interessante sobre a repercussão do crime na cidade foi o depoimento de Tristão José de Araujo no Processo-crime 527, no qual afirma não conhecer os denunciados, mas que sabe do caso por ser público na cidade. A testemunha relata

[...] que teve conhecimento do facto, por ser publico nesta Cidade que os denunciados (um delles que se intitulava Monge), assassinarãm uma preta de nome Eogenia, à poucas léguas desta Cidade, asphixiando-a com um lenço, e que também queimarãm umas crianças não sabendo quantas, sabendo não terem fallecido estas. Perguntado se conhecia os denunciados e qual o procedimento delles? Respondeo que não os conhece, nada podendo affirmar sobre o procedimento d'elles. [...] vio quando os denunciados chegarãm prezos nesta Cidade, e que como já disse sabe por ouvir dizer que os denunciados junctamente assassinarãm a Eogenia. (STJ-PR, 1907, f. 69).

Ao verificar alguns detalhes contraditórios nas deposições das testemunhas, principalmente sobre informações do número de vítimas $\mathrm{e}$ circunstâncias, percebe-se que o ocorrido teve grande impacto para a cidade e envolveu toda a comunidade, pelo fato de o crime ter se tornado "público", ocasionando especulações. 
Além disso, há dois pontos interessantes no depoimento de Tristão José de Araujo: quando indicou a origem da vítima principal ao citála como "preta"; e quando declara que um dos indiciados se intitulava Monge, mas não citando o nome deste. Assim, quando o Juiz deu a palavra aos réus, nenhum deles - especialmente Custodio - contestou a declaração de Tristão, deixando de se defender (diferentemente do que ocorre em todas as declarações que o citam como monge.

Independentemente de se autointitular monge ou não, trabalha-se mediante o imaginário com base na crença de indivíduos destinados a abafar males da vida cotidiana. Essa relação influenciou toda a pesquisa acerca das práticas religiosas tidas da religiosidade popular. Assim, procurou-se conhecer o contexto da região, identificou-se os diferentes grupos sociais para entender de que forma as referidas pessoas vivenciaram essas experiências da religiosidade popular.

\section{Considerações finais}

Considerando não somente a problemática da pesquisa aqui desenvolvida mas também o período de instalação do regime republicano e as tentativas de implantação de um Catolicismo Oficial, o processo-crime resultante de uma prática de exorcismo aqui analisado, não foi apenas casual, visto que seu conteúdo representa a própria contradição dos discursos desenvolvimentistas e de cunho religioso. Por isso, analisar como uma parcela da população vivenciava experiências religiosas tidas como da religiosidade popular em meio a essas populações caboclas fez-se necessário para a problematização desse período histórico, em regiões afastadas dos grandes centros.

Assim as análises do processo e dos jornais ofereceram condicionantes para compreender uma realidade histórico-social da região, discernir grupos socioculturais distintos e seus interesses, conhecer sujeitos históricos atípicos e, inclusive, conhecer regras de convívio. E, ao utilizar episódios transcritos no processo-crime ou circunscritos de origem jornalística, explorando outras instituições vinculadas ao processo, foi possível ponderar acerca da articulação e dos diferentes discursos presentes.

Incorporou as fontes relacionadas à comunicação (imprensa escrita), como os recortes de jornais que comentaram o crime, introduziramse possibilidades de análises em diferentes parâmetros. Nisso, o cruzamento das fontes ofereceu o direcionamento a outros debates pertinentes, pois conceitos e expressões foram, muitas vezes, naturalizadas por parte dos agentes que empregam tais termos. Assim, através da análise da construção dos discursos jornalísticos, problematizou-se como a imprensa tentou classificar indivíduos e padronizálos em determinados rótulos, considerando assim que os jornais se introduzem como fortes formadores de opinião pública.

Esta pesquisa considerou, ainda, atributos envolvendo os sujeitos históricos que, ao longo do processo criminal, foram se incorporando, dando olhares também para questões de cor e vida social de cada grupo existente. Porém, o intuito ao trabalhar dimensões envolvendo os grupos sociais envolvidos, identificando-os como originários de populações caboclas, não restringe a intencionalidade de categorizá-los em determinadas rótulos preestabelecidos negando sua originalidade e historicidade, mas objetiva facilitar o reconhecimento de suas características, utilizando como discussão o sentido sociocultural e não somente as dimensões étnicas para melhor compreendê-los.

Nota-se que um dos principais pontos de fusão cultural foi a religiosidade advinda dessa mistura cultural entre os grupos sociais "recentes" e os convencionais da região. Por isso, por meio do estudo desse caso, observou-se a complexidade de uma realidade histórica, principalmente quando lança esse olhar sobre o meio religioso e cultural que motivou o episódio, que se insere além de questões estritamente ligadas ao próprio caso de exorcismo, mas questões ligadas ao catolicismo popular caboclo.

Constata-se uma atmosfera marcada pelo domínio religioso, tanto no sentido institucional - considerando as tentativas de implantação de um catolicismo oficial - quanto pela presença da religiosidade popular praticada por diferentes comunidades. Afinal, em determinado momento 
histórico, elementos do catolicismo oficial reformador e o catolicismo popular dividiram os mesmos espaços e compartilharam aspectos semelhantes e, por isso, coexistiram.

No caso analisado, de modo geral, observase uma sequência de métodos para a aplicação do dito ritual de exorcismo, desde o batismo, a aplicação medicamentosa, a instauração psicológica e as agressõesfísicas (surra, queimaduras eestrangulação), abarcando outras crenças e superstições dos próprios indivíduos envolvidos que compõem o conjunto da experiência religiosa como um todo.

A religiosidade, nesse sentido, manifestavase também nas formas de se lidar com enfermidades preocupando-se com questões ligadas à cura. Uma cura não somente restrita a abafar males do cotidiano e doenças corriqueiras, mas motivadas pela cura dos males espirituais. Ou seja, um misticismo religioso, relacionando absolvição e remissão dos pecados, ratificação do sacramento, simbologia de passagem, expulsão de espíritos malignos, maus presságios, associações e superstições. Todos esses aspectos são problematizados na composição do ritual de cura espiritual, que não se encerram em si próprios; pelo contrário, abrem ainda mais questionamentos e interpretações.

É interessante notar que, para além da prática do ritual em específico, foram utilizados vários instrumentos durante a experiência religiosa, considerados de feitiçaria ebenzeduras, por exemplo: substâncias medicamentosas; materiais extraídos da natureza como as ervas, as varas de marmelo e o rabo de tatú; e, objetos ligados à devoção, como o rosário e a vela. Materiais esses, que foram entendidos para além de uma ligação devocional, mas relacionados a métodos de coerção, mágico-religioso e relativos a conceitos médicos, os quais foram analisados de forma individual, possibilitando comparações de maneiras de se utilizar o mesmo instrumento com diferentes significados.

Resistindo ao tempo e a suas transformações, as práticas religiosas de curandeirismos, benzeduras e outras aspirações da religiosidade popular vêm sendo reelaboradas e enfrentando pressões constantemente - algumas mais expressivas, outras mais brandas -, sendo interferidas por autoridades científicas, eclesiásticas e pela própria população que utiliza. Portanto, as crenças, os saberes e as práticas culturais são frutos da constituição constante de uma organização social.

\section{Notas}

1 Disponível em: <http://memoria.bn.br/DocReader/ docreader.aspx? bib $=215554 \&$ pasta $=$ ano $\% 20$ 190\&pesq=crime $\% 20 \mathrm{e} \% 20$ fanatismo $>$.

2 Não se trata aqui de um exorcismo levado a cabo pela Igreja oficial, mas resultante de crenças e práticas populares.

3 Outros dois jornais que circularam notícias do crime e também dos envolvidos: A Noticia (1907) e O Commercio (1909).

4 Doravante referenciado de forma simplificada como "Processo-crime 527".

5 Disponíveis em: <bndigital.bn.br/hemerotecadigital/>. Acesso em: 30 mai. 2016.

6 Nas citações de periódicos e textos que tratam sobre o crime, a grafia da época foi mantida; por isso, quaisquer desvios à norma padrão devem ser desconsiderados.

7 Para entendermos melhor as legislações que elevaram Palmas a diversas categorias, Lourdes Lago traz algumas, e ressalta que foi somente em 18 de novembro de 1896 que Palmas foi elevada ã Comarca, "pela Lei de ${ }^{\circ} 233$ " (LAGO, 1987, p. 72-77).

$8 \mathrm{E}$ ainda, “[...] as normas e diligências para a instalação da nova Vila foram baixadas pelo Dr. Rodrigo Otávio de Oliveira Menezes, presidente da Província. O ato de instalação coube ã Câmara Municipal de Guarapuava, e processou-se no dia 14 de abril de 1879" (LAGO, 1987, p. 77).

9 O termo "caboclo" é original do dialeto indígena e, ao longo do tempo, foi sendo "aportuguesado" (SILVA, 2010, p. 68-69). Mas “o ser caboclo" na região recortada pode assumir outras características não restritas somente a questões étnicas e linguísticas, “[...] o caboclo adquire a acepção, ainda viva hoje, de homem do sertão, caipira, roceiro" (CUNHA, 1978, p. 80); além disso, para Paulo Diel, o caboclo sofre uma expropriação cultural e econômica quando se projetou no imigrante europeu o sujeito ideal. A preferência causou uma forte discriminação, acusando o caboclo como um sujeito ignorante, atrasado, promíscuo e fanático, tornandose cativo de sua própria condição, discurso que fundamentou em um amplo processo de marginalização e exclusão (DIEL, 2001, p. 101).

10 Trata-se, muito provavelmente de uma variedade do medicamento conhecida como tártaro emético, na forma de um sal, usado em práticas de cura populares, 
empregado com o propósito de provocar vômitos, (DICCIONARIO DE MEDICINA POPULAR, 1851), usado no tratamento de epilepsia (DICCIONÁRIO DE MEDICINA DOMESTICA E POPULAR, 1865).

11 Ler o subcapítulo "A construção de fatos/verdades na esfera cível" da tese de doutorado de Délcio Marquetti, visto que membros do judiciário também faziam parte das decisões de interesses políticos e econômicos da região. Inclusive o advogado João Manoel da Cunha Sobrinho da defesa dos réus Manoel e Custodio (esse último, somente na $2^{\circ}$ Sessão do Jury) também é reconhecido por Marquetti, que reporta à influência de João Manoel da Cunha Sobrinho que foi professor de primeiras letras em Palmas e, participou politicamente como auxiliar nas questões de limites territoriais entre Santa Catarina e Paraná, além de compor como membro da comunidade jurídica (MARQUETTI, 2015. p. 228-239).

12 O jornal A República teria indicado quatro crianças. Nesse trecho, o jornal cita as duas crianças de Eogenia: "[...] o monge então com o seu instincto de féra, pegou em dois filhos de Eugenia e arremessou nas chammas de um fogo"; neste outro trecho, citam duas crianças da vítima Ignácia dizendo que o monge "pegou duas crianças, Angela e Bibiana” (A REPUBLICA, 1907, p. 2). Mas os autos de corpo de delito constam três crianças; ademais, analisando os depoimentos de todas as testemunhas, as que relatam esse episódio citam somente uma filha de Eogenia e não duas como mencionam os jornais.

\section{Referências}

A NOTICIA. Ed. de 1907. Anno III, n. 416. Curitiba, Quarta-feira, 20 mar.1907, p. 1-2. Disponível em: <http://memoria.bn.br/DocReader/ docreader.aspx? $b i b=215554 \&$ pasta $=$ ano $\% 20$ $190 \&$ pesq $=$ crime $\% 20 \mathrm{e} \% 20$ fanatismo $>$. Acesso em: 7 abr. 2016.

A REPUBLICA. Ed. de 1907. Anno XXII, n.66. Curitiba, Quarta-feira, 20 mar. 1907, p. 2. Disponível em: <http://memoria.bn.br/DocReader/ docreader.aspx $?$ bib $=215554 \&$ pasta $=$ ano $\% 20$ $190 \&$ pesq $=$ crime $\% 20 \mathrm{e} \% 20$ fanatismo $>$. Acesso em: 7 abr. 2016.

CUNHA, A. G. Dicionário histórico das palavras portuguesas de origem tupi. São Paulo: Melhoramentos/EDUSP, 1978.

DIEL, P. F. A reforma católica com o catolicismo popular caboclo no oeste de Santa Catarina e sudoeste do Paraná (1903-1958). Cadernos do CEOM, Chapecó, ano 14, n. 13, p. 99-127, 2001.

GRINBERG, K. A história nos porões dos arquivos judiciários. In: PINSKY, C. B.; LUCA, T. R. de. (Org.). O historiador e suas fontes. São Paulo: Contexto, 2009. p. 119-139.

LAGO, L. S. Origem e evolução da população de Palmas 1840-1899. Florianópolis. 1987. 239 p.

LEVI, G. Sobre a micro-história. In: BURKE, P. (Org.). A escrita da história: novas perspectivas. São Paulo: Editora da UNESP, 1992. p. 133-161.

O COMMERCIO. Curitiba, ed. de 1909, anno II, n. 94, 17 mar. 1909, p. 2-3. Disponível em: $<$ http://memoria.bn.br/DocReader/docreader. aspx $? \mathrm{bib}=215554 \&$ pasta $=$ ano $\% 20190 \&$ pesq $=$ crime \%20e\%20fanatismo>. Acesso em: 7 abr. 2016.

DICCIONÁRIO DE MEDICINA DOMESTICA E POPULAR. Theodoro J. H. Langaardd. Rio de Janeiro: Eduardo \& Henrique Laemmert Editores Proprietários, 1865.

DICCIONARIO DE MEDICINA POPULAR. 2. vol. Pedro Luiz Napoleão Chernoviz - Doutor em Medicina; Cavalleiro da Ordem de Christo. Rio de Janeiro: Eduardo \& Henrique Laemmert Editores Proprietários, 1851.

MARQUETTI, D.; SILVA, J. B. L. da. Cultura cabocla nas fronteiras do Sul. In: RADIM, J. C.; VALENTINI, D. J.; ZARTH, P. A. (Orgs.). História da Fronteira Sul. Porto Alegre: Letras\&Vida: Chapecó: UFFS, 2015, p. 109-129.

RIBEIRO, M. M. Exorcistas e demônios: demonologia e exorcismos no mundo lusobrasileiro. Rio de Janeiro: Campus, 2003.

ROSEMBERG, A.; SOUZA, L. A. F. de. Notas sobre o uso de documentos judiciais e policiais como fonte de pesquisa. Revista Patrimônio e Memória, v. 5, n. 2, p. 168-182, dez. 2009. 
SANTOS, J. dos. Práticas e representações religiosas: o catolicismo no Sudoeste do Paraná (1930-2013). 2014. 266 f. Dissertação (Mestrado em História) - Universidade Estadual do Oeste do Paraná, Marechal Cândido Rondon, 2014.

SILVA, S. S. da. Caboclo. In: MOTTA, M. (Org.). Dicionário da terra. 2. ed. Rio de Janeiro: Civilização Brasileira, 2010. p. 68-69.
SUPERIOR TRIBUNAL DE JUSTIÇA DO ESTADO DO PARANÁ. Palmas/PR. Processo de Apelação Crime. Réu: Custodio Ferreira Soares e outros. Ano 1907. Numeração original: 527.

WACHOWICZ, R. C. Paraná Sudoeste: ocupação e colonização. Curitiba: Lítero-Técnica, 1985. p. 14. 